The Geneva Papers on Risk and Insurance, 14 (No. 51, April 1989), 99-103

\title{
Towards an Integrated Waste Management Program
}

\author{
EDITOR'S INTRODUCTION
}

A challenge facing society today is how to develop a meaningful strategy for undertaking the task of integrated waste management. This was the principal motivation for the conference on "Risk Assessment and Risk Management Strategies for Hazardous Waste Storage and Disposal Problems," held at the Wharton School of the University of Pennsylvania on May 18-19, 1988. The conference brought together representatives from the major interested parties - manufacturing, insurance, government, law, environmental groups and academia - who have been concerned with the waste management process.

The conference specifically made an attempt to understand the opportunities in and limitations of risk assessment as it applies both to landfills targeted for clean-up and to hazardous-waste facilities currently operating. There was an interest in gaining a better understanding of the insurability issues associated with providing coverage for those involved in cleaning up abandoned waste sites and managing current and future facilities. There was also an attempt to develop risk management and communication strategies related to insurance, compensation, and regulation for dealing with hazardous-waste storage and disposal. And it aimed at achieving an understanding of the role of risk communication in the hazardous waste management process. Overall, it aimed to make recommendations for an integrated waste management strategy that recognizes the role of risk assessment and risk management in helping to develop priorities for allocating limited societal resources.

\section{Two hazardous waste-related scenarios}

The following two examples (with fictional names) illustrate the dilemmas both the different concerned parties have in knowing how to deal with the problems associated with hazardous waste:

\section{Example 1: Cleaning up a Landfill}

The U. S. Environmental Protection Agency (EPA) has identified the Leftover Landfill as potentially dangerous to the environment and to the health of nearby inhabitants. The risk assessments of the contents of the landfill indicate that certain chemicals suspected of being carcinogens are present. Four companies have disposed of their wastes in the landfill but there is no easy way to determine what proportion nor the nature of the waste from each company. The local citizens' action group are demanding that the Leftover Landfill be cleaned up in the near future. Should the landfill be cleaned up immediately, and if so, how much should each of the four companies and the EPA pay for cleaning it up? 


\section{Example 2: Managing an Existing Hazardous Waste Facility}

The Wellbent Chemical Company owns a waste treatment facility which is used for the disposal of the toxic waste that the company generates. This facility consists of both an incinerator and a lined landfill for the disposal of incinerator ash. It is also used by other local establishments such as dry cleaners, a small paint factory and the local hospital. Wellbent has been asked by the EPA to show evidence of financial responsibility so that it could provide compensation to victims should there be a hazardous release from the waste treatment center. Wellbent would like to obtain insurance to satisfy this financial responsibility requirement. Should an insurer provide Wellbent with a policy? If so, how much coverage should be offered and what price should be charged?

The large uncertainties associated with the risks associated with hazardous waste make it difficult to determine how to deal with each of the above two examples even in a world without any legal restrictions and specific legislative enactments and government regulations.

\section{Key questions for consideration}

The two examples raise a number of questions regarding the design of hazardous waste policy. Many of these are addressed in the papers which are included in this Special Issue. They also provide a perspective on what types of integrated waste management solutions need to be explored in addressing economic, social, insurance, legal and legislative issues surrounding the hazardous waste management problem.

1. If Leftover Landfill were to be cleaned up, what would be the level of risk that the public would be satisfied with? Is zero risk possible, and practicable? How clean is clean?

2. To what extent can risk assessments clarify the extent of the risks involved with a site and how credible are they? Would risk assessments help us set priorities on the cleanup of Leftover Landfill and other such sites?

3. What are the alternatives to landfills as methods of disposal of wastes? What are the risks involved with them? What can be recommended to Wellbent as a safer method of disposing of its waste than the present incinerator-landfill complex?

4. What further resources need to be requisitioned for the cleanup of Leftover Landfill to take place at the pace and to the level which will satisfy the public?

5. To what extent do inconsistencies exist between the various governmental efforts to regulate environmental pollution? For example, are there inconsistencies between the levels required for cleanup under CERCLA of Leftover Landfill, and the emission requirements for Wellbent's incinerator? How can these be remedied?

6. Are the existing processes adequate to ensure the participation of those affected by hazardous waste sites? Is the local community around Leftover Landfill and Wellbent's facility aware of the hazardous nature of the activities undertaken at these facilities? How can efforts be undertaken to ensure their involvement?

7. What are the data needs for insurers to be able to get a better handle on environmental pollution liability claims that could arise from Wellbent's facility?

8. Given that more than one firm are involved in disposing of their wastes at Wellbent's plant, to what extent does joint and several liability hinder the insurability of environmental pollution risks? Are there methods to insure risks in the face of joint and several liability? 
9. What alternative dispute resolution mechanisms could take the place of tort law to resolve the problems associated with hazardous waste management? These could presumably sort out the issues of who is to pay for what in the cleanup of Leftover Landfill.

10. If carcinogenic effects of the wastes at Leftover Landfill have an impact on the health of people living around it, how can the issue of victims' compensation be adequately addressed? Would an administative scheduled compensation system be the answer?

11. How can public understanding of environmental risks be made better? What role can risk communication play in bringing about a consensus on definitions of risk and acceptable levels of risk?

12. To what extent are risk management approaches being used by the government in the formulation of its policies towards Wellbent? What are the barriers to the use of such approaches?

13. How are the differences between large and small firms being taken into account and addressed in environmental policy making? Do the regulations that affect Wellbent have the same impact on the other small parties utilizing the facility?

14. Is Wellbent sharing its risk management expertise with the other small companies that are disposing of wastes at its plant? What are the obstacles to better information sharing between companies, both large and small? How can these be overcome? By the setting up of institutions to pass and share information on risks, perhaps?

15. What sets of incentives, economic, legal, and regulatory, are necessary to better bring about source reduction, thus ensuring that the Wellbent company changes its technological processes and produces less waste?

16. How can one bring about the involvement in the hazardous waste policy making process of all sections that are affected by it?

17. How can further public involvement and education be brought about, especially at the level of the local communities around Leftover and Wellbent?

18. How can we stimulate research by Wellbent and other companies into new technologies which can tackle the waste problem and yet are "leak-proof"?

19. Are the existing standards in environmental management adequate and are enough resources being directed towards their enforcement at Wellbent and other facilities?

\section{Objectives and plan of the conference}

The papers in this Special Issue develop the elements required for taking the next steps toward an integrated waste management program. There is a need for a long-run strategy to deal with the production, transport and storage of hazardous waste that contrasts the benefits and costs of different actions to society as a whole, while at the same time recognizing the concerns and needs of the affected interested parties. This is a rather tall order as each of the stakeholders has their own agenda which they feel has top priority. The questions posed above related to the two scenarios address different facets of the waste management problem.

The following themes and objectives guided the development of the papers:

(1) To understand the opportunities and limitations of risk assessment of environmental effects from disposal facilities to be cleaned up (e. g., landfills) and hazardous waste facilities currently operating (e. g., incinerators). 
(2) To gain a better understanding of the insurability issues associated with providing coverage for those involved in the clean-up of waste facilities (e. g., potential Superfund sites) and the operation and management of hazardous waste storage and treatment facilities.

(3) To develop a set of risk management and communication strategies related to insurance, compensation and regulation for dealing with hazardous waste storage and disposal problems.

\section{Summary of papers}

The papers are organized in two parts. Part I deals with problems associated with Cleaning Up Hazardous Waste Sites, while Part II covers issues associated with Managing Existing Waste Facilities. In the United States the Comprehensive Environmental Response, Compensation, and Liability Act (CERCLA or Superfund) and its recent amendments addresses the first area while the Resource Conservation and Recovery Act (RCRA) deals with currently operating facilities. Three themes guided the discussion of each of the areas: the need for risk assessments, insurability questions and the development of risk management strategies.

\section{Part I Cleaning Up Existing Waste Sites}

The papers in this part focus primarily on the United States experience of cleaning up inactive Waste Sites under Superfund Risk Assessment Issues: Elizabeth Anderson, Paul Chrostowski and Judy Vreeland in their paper on this issue indicate that there have been significant advances in risk assessment techniques since the EPA formally adopted the use of this approach in evaluating chemicals for their potential toxicity. They stress the importance of conducting risk assessments at sites which may require remediation in order to determine whether a site really needs to be remediated while at the same time specifying priorities for clean-up between sites.

Insurability Issues: Leslie Cheek is rather emphatic that CERCLA deprives both the insurer of the predictability needed to offer coverage. Given the developments in environmental law insurers are uncertain as to what their losses would be should they provide coverage to a potentially responsible party. In fact, given the number of waste sites that must be cleaned up, the insurance industry does not have enough surplus to cover clean-up costs should it be imposed upon them by the courts. Cheek proposes a voluntary arrangement between insurers and potentially responsible parties (PRPs) to work out settlements in cases where there have been a number of insurers who are potentially liable for cleanup losses.

Risk Management Strategies: James Seif and Thomas Voltaggio indicate that risk management strategies should be used for setting priorities on which sites must be cleaned up and then determining what remedial techniques to utilize. With respect to prioritization the EPA utilizes a hazard ranking system which builds on risk assessment data and incorporates waste quantity, degree of toxicity and persistence of the chemical as part of the ranking criteria. When a site is selected for clean-up, a remedial program is utilized based on nine different criteria. The absence of insurance for clean-up contractors and responsible parties poses a challenge for implementing the Superfund program. 


\title{
Part II: Managing Existing Waste Facilities
}

This Part is devoted to the management of existing waste facilities both in the United States and abroad. Two of the papers are written by Europeans who have had extensive experience in developing risk assessment procedures and insurance programs for hazardous waste facilities. The third paper on risk management issues discusses the lessons learned from the implementation of the RCRA program since its enactment in 1976.

Risk Assessment Issues Peter Schroeder describes a procedure which provides a risk profile of an existing waste facility by characterizing the probability and severity of hazards. Risk assessment techniques are utilized to determine where specific hazards lie on a two dimensional probability severity grid and to suggest risk reduction measures. This approach enables insurance premiums to reflect the potential risk associated with the waste facility.

Insurability Issues Baruch Berliner and Juerg Spuehler discuss issues associated with insurability of existing hazardous waste facilities. Berliner points out that hazardous waste risks pose serious challenges to the insurance industry due to great uncertainties about the probability and consequences of the risks and exogenous factors such as liability rules. In the second part of the paper Spuehler shows how different types of pooling arrangements in Europe have provided insurance against pollution problems. He then proposes a liability life policy, an innovative insurance arrangement which provides coverage for the facility from its opening to the time it may close including the post-closure period. Premiums will vary depending on the nature of the facility.

Risk Management Strategies Richard Fortuna focuses on changes in RCRA over time to provide a perspective on risk management strategies. He feels that a strict liability standard, direct and indirect economic incentives and a corporate conscience are necessary for industry to adopt preventive and protective waste management technologies. Fortuna feels that risk assessments should be used to establish national minimum performance standards for existing waste facilities but argues against the use of site-specific risk assessments given the scientific uncertainties which currently exist in characterizing hazards.

I hope that the papers in this Special Issue of the Geneva Papers stimulate an international dialogue on ways that we as a society can develop recommendations for an integrated waste management strategy that recognizes the role of risk assessment and risk management as part of the policy process.

\author{
Howard Kunreuther \\ Center for Risk and Decision Processes \\ The Wharton School \\ University of Pennsylvania
}

